\title{
Role of Nucleus Accumbens Shell Neuronal Ensembles in Context-Induced Reinstatement of Cocaine-Seeking
}

\author{
Fabio C. Cruz, Klil R. Babin, Rodrigo M. Leao, Evan M. Goldart, Jennifer M. Bossert, Yavin Shaham, and Bruce T. Hope \\ Behavioral Neuroscience Branch, IRP/National Institute on Drug Abuse/National Institutes of Health/Department of Health and Human Services, \\ Baltimore, Maryland 21224
}

\begin{abstract}
Environmental contexts previously associated with drug use provoke relapse to drug use in humans and reinstatement of drug seeking in animal models of drug relapse. We examined whether context-induced reinstatement of cocaine seeking is mediated by activation of context-selected nucleus accumbens neurons. We trained rats to self-administer cocaine in Context A and extinguished their lever-pressing in a distinct Context B. On test day, reexposure to the cocaine-associated Context A reinstated cocaine seeking and increased expression of the neural activity marker Fos in 3.3\% of accumbens shell and 1.6\% of accumbens core neurons. To assess a causal role for these activated neurons, we used the Daun02 inactivation procedure to selectively inactivate these neurons. We trained c-fos-lacZ transgenic rats to self-administer cocaine in Context A and extinguished their lever-pressing in Context B. On induction day, we exposed rats to either Context A or a novel Context $\mathrm{C}$ for $30 \mathrm{~min}$ and injected Daun02 or vehicle into accumbens shell or core $60 \mathrm{~min}$ later. On test day, $3 \mathrm{~d}$ after induction day, the ability of Context A to reinstate cocaine seeking and increase neuronal activity in accumbens shell was attenuated when Daun02 was previously injected after exposure to Context A. Daun02 injections after exposure to the novel Context $\mathrm{C}$ had no effect on context-induced reinstatement of cocaine seeking despite much greater numbers of Fos-expressing neurons induced by Context C. Daun02 injections in accumbens core had no effect. Our data suggest that context-induced reinstatement of cocaine seeking is mediated by activation of context-selected accumbens shell but not core neuronal ensembles.
\end{abstract}

Key words: conditioned cues; Daun02 inactivation; drug environment; extinction; Fos; self-administration

\section{Introduction}

In human addicts, environmental contexts associated with previous drug use provoke relapse after prolonged abstinence (O'Brien et al., 1992). In rats, we and others have used variations of the ABA "renewal" procedure (Bouton and Bolles, 1979; Bouton and Swartzentruber, 1991) to study context-induced reinstatement (renewal) of drug seeking (Crombag et al., 2008; Lasseter et al., 2010; Marchant et al., 2012). Renewal refers to the recovery of an extinguished learned response that occurs when the context is changed after extinction (Bouton and Swartzentruber, 1991). In our studies, we train rats to self-administer a drug in one context (Context A); drug infusions are paired with a tone-light compound cue. Next, we extinguish the drugreinforced responding in the presence of the discrete cues in a different (nondrug) context (Context B). Subsequently, we assess

\footnotetext{
Received Jan. 17, 2014; revised March 25, 2014; accepted April 16, 2014.

Author contributions: F.C.C., R.M.L., J.M.B., Y.S., and B.T.H. designed research; F.C.C., K.R.B., R.M.L., E.M.G., and J.M.B. performed research; F.C.C. and B.T.H. contributed unpublished reagents/analytic tools; F.C.C., K.R.B., R.M.L., J.M.B., Y.S., and B.T.H. analyzed data; F.C.C., R.M.L., Y.S., and B.T.H. wrote the paper.

This work was supported by the National Institute on Drug Abuse, Intramural Research Program, National Institutes of Health.

The authors declare no competing financial interests.

Correspondence should be addressed to Dr. Bruce T. Hope, Behavioral Neuroscience Branch, IRP/National Institute on Drug Abuse/National Institutes of Health, 251 Bayview Drive, Baltimore, MD 21224. E-mail: bhope@intra.nida.nih.gov.

DOI:10.1523/JNEUROSCI.0238-14.2014

Copyright $\odot 2014$ the authors $\quad 0270-6474 / 14 / 347437-10 \$ 15.00 / 0$
}

context-induced reinstatement (renewal) of drug seeking in Context A; during the reinstatement tests, lever-presses lead to contingent presentations of the discrete drug cue but not drug (Crombag and Shaham, 2002).

Learned associations between environmental contexts and discrete cues and drug effects are thought to be encoded by sparsely distributed patterns of neurons called "neuronal ensembles" (Carelli, 2002; Cruz et al., 2013). Correlational data from in vivo electrophysiology studies indicate that specific sets of neurons in nucleus accumbens fire in a time-locked manner in response to drug-associated contexts or discrete cues (Pennartz et al., 1994; Woodward et al., 1999; Deadwyler et al., 2004). Similar correlations have been observed for the expression of the neural activity marker Fos after exposure to drug-associated contexts or discrete cues (Neisewander et al., 2000; Hamlin et al., 2008; Bossert et al., 2012). However, because of the correlational nature of electrophysiology and Fos-mapping studies, it is unknown whether the activated neurons mediate or play a causal role in context- or discrete-cue-induced drug seeking.

To address this problem, we developed the Daun02 inactivation procedure (Koya et al., 2009) to assess causal roles of activated neurons in context- or discrete-cue-induced drug seeking and other learned behaviors. The Daun02 inactivation method uses $c$-fos-lac $Z$ transgenic rats where $\beta$-galactosidase $(\beta \mathrm{gal})$ and Fos are coexpressed within activated neurons (Kasof et al., 1995). Ninety minutes after rats perform a behavioral task, the activated 
neurons are inactivated by injecting the prodrug Daun02 into a given brain area. $\beta$ gal within the activated neurons converts Daun02 into daunorubicin (Farquhar et al., 2002), which disrupts normal function of these neurons for at least $3 \mathrm{~d}$ (Cruz et al., 2013). We previously used the Daun02 inactivation procedure to assess causal roles of neuronal ensembles in context-specific cocaine psychomotor sensitization, context-induced reinstatement of heroin seeking, and time-dependent increases in cue-induced heroin seeking after withdrawal (Koya et al., 2009; Bossert et al., 2011; Fanous et al., 2012).

Fuchs et al. (2008) previously reported that reversible inactivation of accumbens core or shell by muscimol + baclofen (GABAa + GABAb agonists) or glutamate receptor antagonists decrease context-induced reinstatement of cocaine seeking (Fuchs et al., 2008; Xie et al., 2012). Here, we used the Daun02 inactivation procedure to examine whether context-induced reinstatement of cocaine seeking is mediated by context-activated neuronal ensembles in accumbens core or shell. We also used double-labeling immunohistochemistry to characterize these Fos-expressing neurons.

\section{Materials and Methods}

Animals. We used a total of 120 male Sprague Dawley rats (Charles River) and male $c$-fos-lac $Z$ transgenic rats that weighed 350-450 $\mathrm{g}$ at the time of surgery. After surgery, the rats were housed individually in the animal facility under a reverse $12 \mathrm{~h}$ light-dark cycle (lights off at 8:00 A.M.). Water was freely available in the rats' home cages throughout the experiments, and food was restricted to $20 \mathrm{~g}$ per day of Purina rat chow (given after the daily operant sessions).

All procedures followed the guidelines outlined in the Guide for the care and use of laboratory animals (Ed 8; http://grants.nih.gov/grants/ olaw/Guide-for-the-Care-and-Use-of-Laboratory-Animals.pdf). From all experiments, we excluded 28 of the 120 rats: 10 for inadequate training ( $<10$ infusions/d on the lower cocaine training dose $0.5 \mathrm{mg} / \mathrm{kg} /$ infusion) or failure to meet an extinction criterion of a mean of $<25$ responses per $3 \mathrm{~h}$ over $3 \mathrm{~d}$ after 25 extinction sessions, 10 for misplaced cannulae (Experiment 3; rostral to 2.5 or caudal to 0.5 from bregma), and 8 because they lost their head caps.

Intracranial and intravenous surgery. Rats were anesthetized with ketamine and xylazine ( 80 and $20 \mathrm{mg} / \mathrm{kg}$, i.p.), and permanent guide cannulae (23-gauge, Plastics One) were implanted bilaterally $1 \mathrm{~mm}$ above the accumbens shell or core. We used the same stereotaxic coordinates (Paxinos and Watson, 2005) used in our previous studies (Koya et al., 2009; Bossert et al., 2012). The nose bar was set at $-3.3 \mathrm{~mm}$, and the coordinates for accumbens shell were anteroposterior $1.7 \mathrm{~mm}$, mediolateral $\pm 3.8 \mathrm{~mm}\left(25^{\circ}\right.$ angle $)$, and dorsoventral $-6.8 \mathrm{~mm}$, and for accumbens core were anteroposterior $1.7 \mathrm{~mm}$, mediolateral $\pm 2.5 \mathrm{~mm}\left(6^{\circ}\right.$ angle), and dorsoventral $-6.0 \mathrm{~mm}$ ). After cannulae implantation, silastic catheters were inserted into the jugular vein, as described previously (Bossert et al., 2004, 2006). Catheters were attached to a modified 22gauge cannula and mounted to the rat's skull with dental cement. Buprenorphine $(0.1 \mathrm{mg} / \mathrm{kg}$, s.c.) was given after surgery to relieve pain, and rats were allowed to recover for $7-10 \mathrm{~d}$ before cocaine selfadministration training. During the recovery and training phases, catheters were flushed every 24-48 h with gentamicin (Butler Schein; $5 \mathrm{mg}$ / $\mathrm{ml}$ ) and sterile saline. In Experiment 1, we implanted only intravenous catheters.

Intracranial injections. Daun02 or vehicle was injected into accumbens shell or core on induction day. Daun02 was obtained from Sequoia Research Products (www.seqchem.com). Daun02 (2 $\mu \mathrm{g} / 0.5 \mu \mathrm{l} / \mathrm{side}$ ) was dissolved in 5\% DMSO, 6\% Tween 80, and 89\% $0.01 \mathrm{~m}$ PBS. The dose of Daun02 was based on previous studies (Koya et al., 2009; Bossert et al., 2011; Fanous et al., 2012). Intracranial injections were administered using a syringe pump (Harvard Apparatus) and 2 or $10 \mu \mathrm{l}$ Hamilton syringes that were attached via polyethylene- 20 or -50 tubing, respectively, to 30-gauge injectors (Plastics One) that extended $1 \mathrm{~mm}$ beyond the guide cannula. Daun02 or vehicle was injected over $1 \mathrm{~min}$, and the injectors were left in place for $1 \mathrm{~min}$ before removal.

Self-administration chambers and experimental contexts. Rats were trained and tested in Med Associates self-administration chambers. Each chamber was equipped with two levers located $9 \mathrm{~cm}$ above the grid floor. Presses on the active retractable lever activated the infusion pump, whereas presses on the inactive nonretractable lever had no programmed consequences. Two different Contexts A and B, previously described (Bossert et al., 2011, 2012), were used for self-administration training and extinction phases. These contexts had different auditory (fan turned on or off), visual (red or white house light), tactile (different size rods in floor), and circadian (morning [onset at 8:00 A.M. to 9:00 A.M.] or afternoon [onset at 2:00 P.M. to 3:00 P.M. pm] sessions) cues. An additional Context $\mathrm{C}$ was used as a novel control environment that consisted of a round bowl with bedding and toys placed in a different room from Contexts A and B.

Self-administration training, extinction, and context-induced reinstatement. The experiments consisted of 3 phases: self-administration training (12 d), extinction training (12-25 d), and tests for context-induced reinstatement of cocaine seeking $(1 \mathrm{~d})$. The experimental sequence was Context A (training) —Context B (extinction) —Contexts A-C (testing). Contexts A and B and circadian cues were counterbalanced for all experiments. However, for explanation purposes, we refer to the cocaine selfadministration training context as Context $\mathrm{A}$ and the extinction context as Context B.

Rats were trained to self-administer cocaine for $3 \mathrm{~h} / \mathrm{d}$ for $12 \mathrm{~d}$. Cocaine (cocaine $\mathrm{HCl}$, National Institute on Drug Abuse) was dissolved in sterile saline and infused at a volume of $65 \mu \mathrm{l}$ over $2.3 \mathrm{~s}$ at a dose of 1.0 (first 6 sessions) and 0.5 (last 6 sessions) $\mathrm{mg} / \mathrm{kg} /$ infusion. During training in Context $\mathrm{A}$, cocaine infusions were earned under a fixed ratio $1,20 \mathrm{~s}$ timeout reinforcement schedule and were paired with a compound tone (2900 Hz; $20 \mathrm{~dB}$ above background) light (a $7.5 \mathrm{~W}$ white light) cue for $2.3 \mathrm{~s}$. During the extinction phase in Context B, responses on the previously active lever led to presentation of the tone-light cue but not cocaine. Tests for context-induced reinstatement were conducted under extinction conditions (lever-presses led to the presentation of the tone-light cue but not cocaine) and began after a minimum of 12 daily extinction sessions when the rats met extinction criterion of a mean of $<25$ presses on the previously active lever over the last three extinction sessions.

Experiment 1: context-induced reinstatement of cocaine seeking and Fos expression. A total of 34 rats were used in this experiment. The test group (A-B-A) underwent cocaine self-administration training in Context A, extinction training in Context $\mathrm{B}$, and 90 min reinstatement testing in Context A. The control groups (A-B-B and A-B-C) underwent cocaine self-administration training in Context $A$, extinction training in Context $\mathrm{B}$, and 90 min reinstatement testing in Context B or 90 min exposure to Context $\mathrm{C}$, respectively. Rats in the control and test groups were matched for their cocaine intake and number of active lever-presses during the training and extinction phases. At the end of the test session, rats were deeply anesthetized with isoflurane and perfused with $100 \mathrm{ml}$ of PBS followed by $400 \mathrm{ml}$ of $4 \%$ PFA. The brains were postfixed in PFA for 90 min and transferred to $30 \%$ sucrose in PBS solution at $4^{\circ} \mathrm{C}$ for $2-3 \mathrm{~d}$. Brains were frozen in powdered dry ice and kept at $-80^{\circ} \mathrm{C}$ until sectioning. Coronal sections were cut $40 \mu \mathrm{m}$ thick between bregma 2.2 and 1.6 $\mathrm{mm}$ (Paxinos and Watson, 2005). Free-floating sections were washed three times in PBS, blocked with 3\% NGS in PBS with $0.25 \%$ Triton $\mathrm{X}-100$ (PBS-Tx), and incubated $24 \mathrm{~h}$ at $4^{\circ} \mathrm{C}$ with anti-Fos antibody (1: 4000 dilution, catalog \#sc-52; Santa Cruz Biotechnology) in blocking solution. Sections were washed again with PBS and incubated for $2 \mathrm{~h}$ in biotinylated goat anti-rabbit secondary antibody (1:600 dilution; Vector Laboratories) in PBS-Tx and 1\% NGS. After washing in PBS, sections were incubated for $1 \mathrm{~h}$ in avidin-biotin-peroxidase complex (ABC Elite kit, catalog \#PK-6100; Vector Laboratories) in PBS containing 0.5\% Triton X-100. Finally, sections were washed in PBS and developed in DAB for $\sim 3 \mathrm{~min}$, transferred into PBS, and mounted onto chromalumgelatin-coated slides. Once dry, the slides were dehydrated through a graded series of alcohol $(30 \%, 60 \%, 90 \%, 95 \%, 100 \%, 100 \%$ ethanol) and 
cleared with Citrasolv (Fisher Scientific) before coverslipping with Permount (Sigma).

Bright-field images of immunoreactive (IR) cells in accumbens shell and core were digitally captured using a EXi Aqua camera (QImaging; www.qimaging.com) attached to a Zeiss Axioskop 2 microscope at $100 \times$ magnification (Carl Zeiss Microscopy) and iVision software for Macintosh, version 4.0.15 (Biovision). Labeled nuclei from two sections (bilateral) per rat were counted automatically (four images per rat) and averaged so that each rat was an $n$ of 1 for each brain area.

Characterization of Fos-expressing neurons using double-labeling immunohistochemistry. We used double-label immunohistochemistry to characterize accumbens neurons activated during the reinstatement tests. For these assays, we used sections obtained from a subset of the brains used in the previous Fos immunohistochemistry assays (4 rats from each group). All rats were perfused with PFA 90 min after the beginning of the reinstatement test, and their brains were processed as described above and kept at $-80^{\circ} \mathrm{C}$ until sectioning. Coronal sections were cut between bregma 2.2 and $1.6 \mathrm{~mm}$ (Paxinos and Watson, 2005).

We first determined the proportion of all accumbens shell and core neurons expressing Fos during the reinstatement test by doublelabeling for Fos and the neuron-specific protein NeuN (Mullen et al., 1992). Sections $(40 \mu \mathrm{m})$ were washed three times in TBS and permeabilized for $30 \mathrm{~min}$ in TBS with $0.2 \%$ Triton X-100. Sections were then incubated with rabbit anti-Fos (1:400 dilution, catalog \#sc-52, Santa Cruz Biotechnologies) and biotinylated mouse anti-NeuN (1:2000 dilution, catalog \#MAB37, EMD Millipore) diluted in TBS with $0.2 \%$ Triton X-100 for $20 \mathrm{~h}$ on a shaker at $4^{\circ} \mathrm{C}$. Sections were washed three times in TBS and incubated with secondary fluorescent labels AlexaFluor 488-labeled donkey anti-rabbit IgG antibody (1:200 dilution, catalog \#A-10042, Invitrogen) and AlexaFluor-350-labeled streptavidin (1:2000 dilution, catalog \#S-11249, Invitrogen) diluted in TBS with $0.2 \%$ Triton $\mathrm{X}-100$ for $2 \mathrm{~h}$ on a shaker at room temperature. Sections were washed in TBS, mounted onto chromalum-gelatincoated slides, and coverslipped with VectaShield hard-set mounting media (Vector Laboratory).

Fluorescent images of accumbens were captured with an EXi Aqua camera (QImaging) attached to a Zeiss AXIO Imager M2 microscope at $200 \times$ magnification (Carl Zeiss Microscopy) and iVision software for Macintosh, version 4.0.15 (Biovision). Labeled nuclei were counted automatically from two sections per rat. We then assessed the phenotype of Fos-expressing neurons by double labeling for Fos and either a marker of medium spiny neurons (DARPP-32), or markers for different subtypes of GABAergic interneurons (parvalbumin, somatostatin, calretinin), or a marker of cholinergic neurons (choline acetyltransferase) using a twostep immunohistochemical procedure described previously (Morales et al., 1998; Bäckman and Morales, 2002; Bossert et al., 2012). In the first immunolabeling step, free-floating sections $(40 \mu \mathrm{m})$ were rinsed ( 3 times for $10 \mathrm{~min}$ each) in PBS and incubated for $1 \mathrm{~h}$ in 3\% NGS in PBS-Tx. Sections were then incubated with rabbit anti-Fos primary antibody (sc52, Santa Cruz Biotechnology) diluted 1:4000 in 3\% NGS in PBS-Tx. Sections were rinsed in PBS and incubated for $2 \mathrm{~h}$ with biotinylated anti-rabbit IgG secondary antibody (BA-1000, Vector Laboratories), diluted 1:600 in 1\% NGS in PBS-Tx. Sections were rinsed in PBS and incubated with the avidin-biotin-peroxidase complex (ABC Elite kit, catalog \#PK-6100, Vector Laboratories) in PBS-Tx (0.5\%) for $1 \mathrm{~h}$. Sections were rinsed in PBS and peroxidase labeling developed using Vector SG (blue/gray product; Vector SG peroxidase substrate kit, Vector Laboratories). This reaction was terminated by rinsing the tissue in $0.1 \mathrm{~m}$ Tris$\mathrm{Cl}, \mathrm{pH}$ 7.4. To quench remaining peroxidase activity from the first immunolabeling step, sections were rinsed 3 or 4 times in PBS, incubated in $0.3 \% \mathrm{H}_{2} \mathrm{O}_{2}$ for $30 \mathrm{~min}$, and then rinsed before incubation for $1 \mathrm{~h}$ in PBS-Tx containing 4\% BSA and avidin D (avidin-biotin blocking kit, catalog \#SP 2001, Vector Laboratories). For the second immunolabeling step, sections were incubated overnight at $4^{\circ} \mathrm{C}$ with rabbit antiDARPP-32 (1:500 dilution, catalog \#611520; BD Bioscience), rabbit anticalretinin (1:100 dilution, catalog \#AB5954; Millipore), rabbit anti- somatostatin (1:4000 dilution, catalog \#A0566, Dako), mouse antiparvalbumin (1:40,000 dilution, catalog \#P3088; Sigma-Aldrich), or goat anti-Chat (1:20,000 dilution, catalog \#AB144P; Millipore) in 4\% BSA, PBS-Tx, and biotin. Sections were then rinsed in PBS and incubated for $1 \mathrm{~h}$ with biotinylated anti-rabbit, anti-mouse, or anti-goat IgG secondary antibodies (BA-1000, BA-9200, and BA-5000, respectively, Vector Laboratories) diluted $1: 200$ in $4 \%$ BSA in PBS-Tx $(0.3 \%)$. Sections were rinsed in PBS and incubated with the ABC reagent in PBS for $1 \mathrm{~h}$. Sections were rinsed in PBS and developed in DAB for 5 min, rinsed in PBS, mounted onto chrom-alum/gelatin-coated slides, and air-dried. Slides were dehydrated through a graded series of ethanol concentrations, cleared with Citrasolv (Fisher Scientific), and coverslipped with Permount (Sigma).

Bright-field images of nucleus accumbens were digitally captured using an EXi Aqua camera (QImaging) attached to a Zeiss Axioskop 2 at $100 \times$ magnification (Carl Zeiss Microscopy) and iVision software for Macintosh, version 4.0.15 (Biovision). Labeled cells from 4 hemisections per rat were manually counted and averaged so that each rat was an $n$ of 1 .

Experiments 2 and 3: Daun02 inactivation of selectively activated neurons in accumbens shell (Exp. 2) and core (Exp. 3). We used the Daun02 inactivation procedure to determine a functional role for activated Fosexpressing accumbens neurons in context-induced reinstatement (Koya et al., 2009; Cruz et al., 2013). Seventy transgenic $c$-fos-lacZ rats (previously bred for $45-50$ generations on a Sprague Dawley background) were anesthetized and implanted with permanent bilateral guide cannulae (23-gauge, Plastics One) as described above. The experimental timeline is shown in Figure $4 A$. Briefly, four groups of rats ( $n=10-14$ per group) were used. Rats were trained to lever-press for cocaine in Context $\mathrm{A}$, and lever-pressing was extinguished in Context $\mathrm{B}$. Then on induction day, the rats were exposed to Context $\mathrm{A}$ (cocaine context; two groups) or Context $\mathrm{C}$ (novel context; two groups) for $30 \mathrm{~min}$. The rats were then placed in their home cages for an additional $60 \mathrm{~min}$ before intracranial injections of Daun02 or vehicle (5\% DMSO and 5\% Tween 80 in PBS) into either accumbens shell or core and returned to their home cage. For the next $2 \mathrm{~d}$, all rats were given two $3 \mathrm{~h}$ extinction sessions in Context $\mathrm{B}$. We incorporated these two extinction sessions between induction day and test day to verify that Daun02 injections had no effect on extinction responding in Context B and to ensure low operant responding in both the vehicle and Daun02 groups in this context before testing for context-induced reinstatement in Context A. The next day, the rats were tested for context-induced reinstatement in Context A (90 min session). At the end of the test session, the rats were anesthetized, perfused with PBS and 4\% PFA, and their brains were removed for subsequent $\beta$ gal labeling. Rats in the vehicle and Daun02 groups were matched for their previous cocaine intake and number of active leverpresses during training, extinction, and induction day.

We used X-gal histochemistry to visualize $\beta$ gal as an indicator of neuronal activation. Free-floating sections $(40 \mu \mathrm{m})$ were washed three times for 10 min each in PBS and incubated in reaction buffer (2.4 mM X-gal, $100 \mathrm{~mm}$ sodium phosphate, $100 \mathrm{~mm}$ sodium chloride, 5 mм EGTA, $2 \mathrm{~mm} \mathrm{MgCl}_{2}, 0.2 \%$ Triton X-100, $5 \mathrm{~mm} \mathrm{~K}_{3} \mathrm{FeCN}_{6}, 5 \mathrm{~mm}$ $\mathrm{K}_{4} \mathrm{FeCN}_{6}$ ) for $4.5 \mathrm{~h}$ at $37^{\circ} \mathrm{C}$ with gentle shaking. Sections were washed 3 times for 10 min each in PBS and mounted onto chromalumgelatin-coated slides and air-dried. Slides were dehydrated through a graded series of ethanol, cleared with Citrasolv, and coverslipped with Permount. Bright-field images of $\beta$ gal-expressing nuclei in accumbens shell and core were digitally captured using an EXi Aqua camera (QImaging) attached to a Zeiss Axioskop 2 at $100 \times$ magnification (Carl Zeiss Microscopy). Bgal-expressing nuclei, characterized by blue nuclear staining, were counted using using iVision for Macintosh, version 4.0.15 (Biovision). Labeled nuclei were automatically counted in a sampling area $\left(\sim 1.09 \mathrm{~mm}^{2}\right)$ around the accumbens shell and core injection sites in the left and right hemispheres of each rat. Counts from each rat were averaged so that each rat was an $n$ of 1 .

Statistical analyses. The behavioral and immunohistochemical data were analyzed by one-way and two-way ANOVAs using Prism (Graphpad Software). Fisher's PLSD was used for post hoc analyses 
when ANOVAs indicated significant main or interaction effects $(p<0.05)$.

\section{Results}

Training and extinction: Experiments 1-3 Figure $1 A$ shows the mean \pm SEM number of cocaine infusions and presses on the active and inactive levers during the training phase in Context $\mathrm{A}$ in Experiments 1-3. In each experiment, the rats demonstrated reliable cocaine self-administration, as indicated by the increase in number of infusions and active lever-presses when the cocaine dose was decreased from 1.0 to 0.5 $\mathrm{mg} / \mathrm{kg} /$ infusion on training day $7(p<$ 0.01 ). Figure $1 B$ shows the mean \pm SEM number of lever-presses on the previously active and inactive levers during the first 12 extinction sessions in Context B in Experiments 1-3. As expected, during the extinction phase, active lever-presses decreased over time $(p<0.01)$.

Context-induced reinstatement of cocaine seeking and novelty exposure are associated with increased Fos expression in nucleus accumbens Context-induced reinstatement

On test day, we exposed separate groups of rats to cocaine Context $\mathrm{A}$, extinction Context B, or a novel Context C. We assessed context-induced reinstatement by assessing nonreinforced lever-presses in Context A versus Context B (Fig. 2A). We analyzed the reinstatement test data by mixed ANOVA, using the betweensubjects factor of context (Context A, Context B) and the within-subjects factor of lever (active, inactive). This analysis indicated a significant interaction between these factors $\left(F_{(1,20)}=25.1, p<0.01\right)$. Post hoc group differences are indicated in Figure $2 A$.

\section{Fos expression}

We first analyzed Fos expression in accumbens shell and core using the between-subjects factor of context (training cocaine Context A, extinction Context $\mathrm{B}$, novel Context $\mathrm{C}$ ) and the withinsubjects factor of accumbens region (core, shell). The factorial ANOVA showed a main effect of context $\left(F_{(2,40)}=78.7, p<\right.$ $0.01)$ but no significant interaction be-

tween the two factors $(p=0.16)$. This main effect of context was the result of a significantly higher Fos expression in the novel Context C compared with Contexts A and B (Fig. 2). Therefore, we also analyzed the data after excluding Context $\mathrm{C}$ data. This analysis showed a significant interaction between context (Context $\mathrm{A}$, Context $\mathrm{B})$ and accumbens region (core, shell) $\left(F_{(1,27)}=\right.$ $5.8, p<0.05)$. This interaction is the result of higher Fos expression in accumbens shell than core after exposure to Context A but not Context B $(p<0.05)$.
A Self-administration training (Context A)
B Extinction training
(Context B)

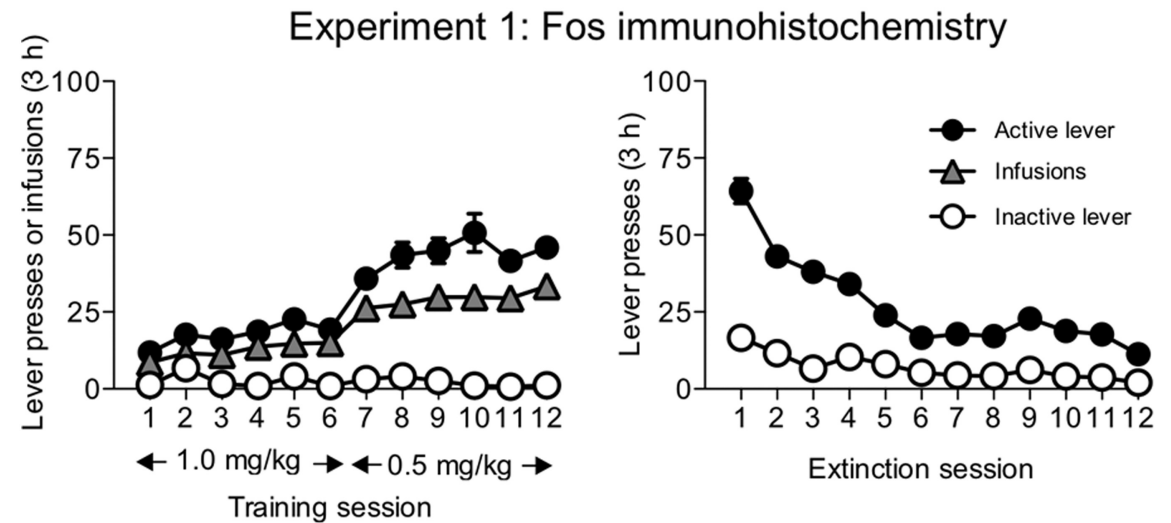

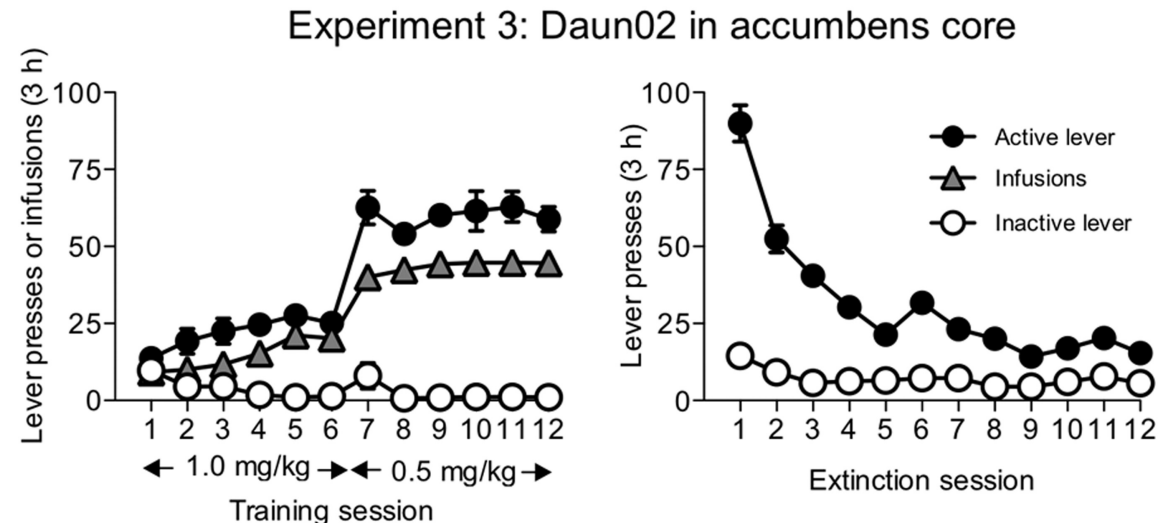

Figure 1. Cocaine self-administration training and extinction of drug-reinforced responding. $A$, Rats were trained to selfadminister cocaine using $1 \mathrm{mg} / \mathrm{kg} /$ infusion for the first $6 \mathrm{~d}$ and $0.5 \mathrm{mg} / \mathrm{kg} /$ infusion for the next $6 \mathrm{~d}$. Data are mean \pm SEM number of infusions, and active and inactive lever-presses during cocaine self-administration training in Context $A$ in Experiment 1 ( $n=$ 34), Experiment $2(n=42)$, and Experiment $3(n=21) \cdot \boldsymbol{B}$, Mean \pm SEM number of presses on the active lever and inactive lever during the first 12 extinction sessions conducted in the absence of cocaine in a different (Extinction) Context B in Experiments 1-3.

Characterization of Fos-expressing neurons using double-labeling immunohistochemistry

We used double-labeling immunohistochemistry to determine the percentage and cellular phenotype of Fos-expressing neurons in sections obtained from a subset of the brains used in the Fos immunohistochemistry assays ( 4 rats from each group). Doublelabeling for Fos and the general neuronal marker NeuN indicated that only a small proportion of neurons were activated. In accumbens shell, Fos was expressed in $0.7 \pm 0.4 \%, 3.3 \pm 0.8 \%$, and 
D Fos-IR nuclei

\section{A Context-induced reinstatement of cocaine seeking}

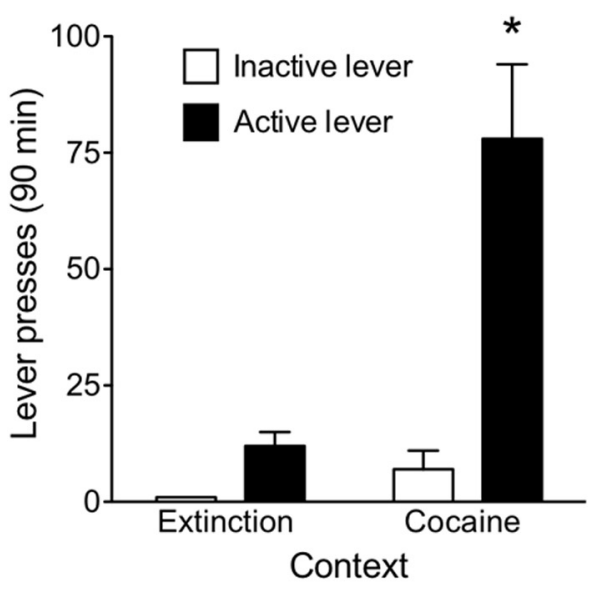

B Fos-IR nuclei in accumbens shell

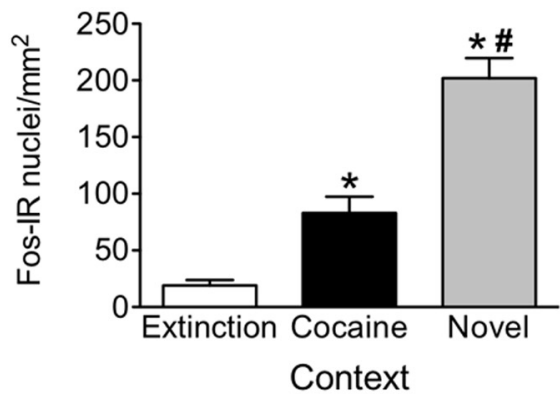

C Fos-IR nuclei in accumbens core

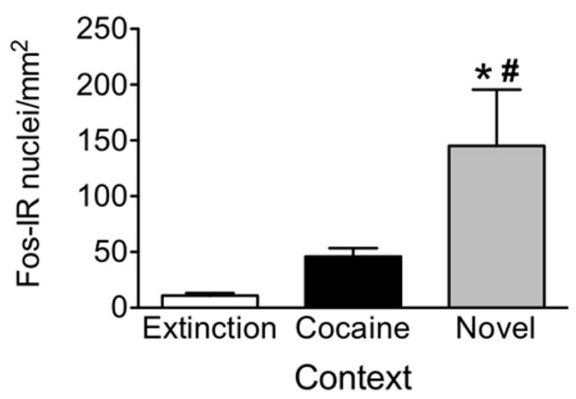

Accumbens Core

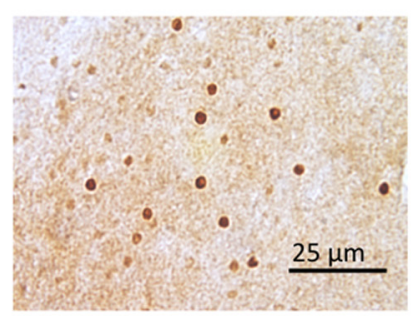

Accumbens Shell

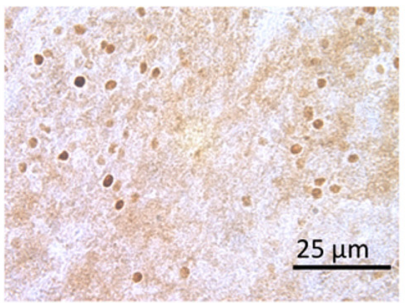

Extinction Context

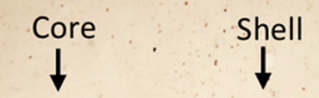

$\underline{100 \mu \mathrm{m}}$
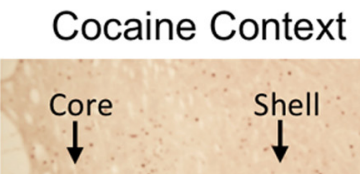

$\underline{100 \mu \mathrm{m}}$

Novel Context

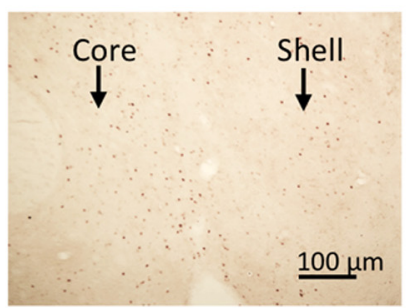

Figure 2. Context-induced reinstatement of cocaine seeking is associated with Fos induction in accumbens shell. $\boldsymbol{A}$, Reinstatement test: Total number of active lever and inactive lever-presses in rats tested in the Extinction or Cocaine context. Data are mean \pm SEM. ${ }^{*} p<0.05$, different from the Extinction context. $n=10$ or 11 per group. $\boldsymbol{B}$, Number of Fos-IR nuclei per $\mathrm{mm}^{2}$ in accumbens shell. Data are mean \pm SEM. C, Number of Fos-IR nuclei per $\mathrm{mm}^{2}$ in accumbens core. $\boldsymbol{D}$, Top two panels, Fos-IR nuclei in accumbens core and shell captured at $400 \times$ magnification. Bottom three panels, $100 \times$ magnification of areas used for quantifying Fos-IR neurons in accumbens shell and core of rats that were exposed to Extinction, Cocaine, and Novel contexts. ${ }^{*} p<$ 0.05 , different from the Extinction context. ${ }^{\#} p<0.05$, different from the Cocaine context. $n=8-11$ per group.

$12.1 \pm 1.2 \%$ of all neurons after exposure to the extinction, cocaine, and novel contexts, respectively (Fig. $3 A$ ), In accumbens core, Fos was expressed in $0.4 \pm 0.1 \%, 1.6 \pm 0.1 \%$, and $6.1 \pm$ $0.2 \%$ of all neurons after exposure to the extinction, cocaine, and novel contexts, respectively (Fig. $3 B$ ).

We also assessed cellular phenotypes of these Fos-expressing neurons (Table 1 ). The majority of Fos-expressing neurons colabeled with DARPP-32, indicating that they are medium spiny neurons. The remaining Fos-expressing neurons were composed of different subtypes of GABAergic interneurons (parvalbumin, calretinin, somatostatin subtypes), as well as cholinergic interneurons. In general, the proportions of Fos-expressing cells resemble the general proportions of these cell types in accumbens (Meredith et al., 1992; Zahm, 1992), with the exception of a larger contribution from parvalbumin interneurons.

\section{Daun02 inactivation of activated} accumbens shell decreased contextinduced reinstatement of cocaine seeking

We used the previously described Daun02 inactivation procedure (Koya et al., 2009) to determine whether the Fos-expressing neurons activated by cocaine Context A play a causal role in context-induced reinstatement of cocaine seeking (experimental timeline in Fig. 4A). Because of more robust expression of Fos in accumbens shell (Fig. 2), we first injected Daun02 or vehicle into this subregion during the induction day and assessed context-induced reinstatement after two additional extinction sessions in Context B.

\section{Context-induced reinstatement}

We analyzed the active lever-press data during the test day with a two-way ANCOVA using the between-subjects factors of induction context $(\mathrm{A}, \mathrm{C})$ and drug (vehicle, Daun02), and the covariate of active lever-presses on the second day of extinction in Context B (between induction and test day). This analysis showed a significant interaction between induction context and drug $\left(F_{(1,42)}=4.0\right.$, $p<0.05$; Fig. 4C). Post hoc analysis indicated that Daun02 decreased the number of active-lever-presses on test day in Context A when injected after exposure to cocaine Context A $(p<0.05)$, but not after exposure to the novel Context $\mathrm{C}$, on induction day. Daun02 injections had no effect on active lever-presses in extinction Context $\mathrm{B}$ on the day before the test session (Fig. 4B) or inactive lever-presses during this extinction session or the test session ( $p>0.05$; Table 2). Cannula placements are shown in Figure $4 D$.

Bgal expression

The two-way ANOVA indicated a significant main effect of Context $\left(F_{(1,36)}=5.1 ; p<0.05\right)$ and an approaching significant interaction between Daun 02 condition and Context $\left(F_{(1,36)}=3.64\right.$, 
$p=0.06)($ Fig. $4 E, F)$. Daun02 significantly decreased the number of $\beta$ gal expressing neurons when injected following exposure to Cocaine Context A $(p<0.05)$ but not the Novel Context $\mathrm{C}(p>0.05)$.

\section{Daun02 inactivation of activated accumbens core did not alter context- induced reinstatement of cocaine seeking}

On induction day, we injected Daun02 or vehicle into accumbens core after exposure to cocaine Context A and tested for context-induced reinstatement in Context $\mathrm{A}$ after two additional extinction sessions in Context B.

\section{Context-induced reinstatement}

We analyzed the active lever-press data during the test day with one-way ANCOVA using the between-subjects factor of drug (vehicle, Daun02) and the covariate active lever-presses on the second day of extinction in Context B. This analysis showed that the drug effect was not significant $\left(F_{(1,19)}=1.01, p>0.1\right.$; Fig. $5 B)$. Daun02 injections had no effect on active lever-presses in extinction Context $\mathrm{B}$ on the day before the test session (Fig. $5 A$ ) or inactive leverpresses during this extinction session or the test session $(p>0.05$; see Table 2). Cannula placements are shown in Figure $5 C$.

\section{Bgal expression}

Daun02 injections significantly decreased $\beta$ gal labeling $\left(t_{(15)}=\right.$ 9.2, $p<0.001$; Fig. $5 D, E)$.

\section{Discussion}

We studied the role of cocaine context-activated accumbens neuronal ensembles in context-induced reinstatement of cocaine seeking. As in previous reports (Crombag and Shaham, 2002), drug seeking was induced by reexposure to the drug-associated context after extinction of drug self-administration in a different context. Context-induced cocaine seeking also increased Fos expression in $3.3 \%$ of accumbens shell and $1.6 \%$ of accumbens core neurons. The majority of these Fos-expressing neurons were medium spiny neurons, whereas the remaining Fos-expressing neurons were composed of different subtypes of GABAergic interneurons (parvalbumin, calretinin, somatostatin subtypes) and cholinergic interneurons.

Most important, we found that context-induced reinstatement of cocaine seeking and accumbens shell activity were attenuated by selective inactivation of the Fos- and $\beta$-gal-expressing accumbens shell neurons that were previously activated by exposure to the cocaine-associated context. In contrast, Daun02 inactivation of Fos- and $\beta$ gal-expressing neurons that were previously activated by exposure to the novel Context $C$ had no effect on subsequent context-induced reinstatement and accumbens shell activation. Furthermore, Daun02 injections into accumbens core had no effect on context-induced reinstatement of cocaine seeking. These data suggest that contextinduced reinstatement of cocaine seeking is mediated by activation of context-selected accumbens shell but not core neuronal ensembles.
Table 1. Specific cell types of Fos-expressing neuronal ensembles that were activated by exposure to the training context (Context $A$ ) or the extinction context (Context B) $^{a}$

\begin{tabular}{lcc}
\hline Fos cell types & Extinction context & Cocaine context \\
\hline DARPP-32 & $58.1 \pm 11.4$ & $69.4 \pm 3.6$ \\
Parvalbumin & $17.7 \pm 4.7$ & $12.9 \pm 0.1$ \\
Calretinin & $2.2 \pm 2.2$ & $1.6 \pm 1.3$ \\
Somatostatin & $6.6 \pm 1.5$ & $6.7 \pm 3.7$ \\
Choline acetyltransferase & Not detectable & $3.7 \pm 03$ \\
\hline
\end{tabular}

${ }^{a}$ Data are mean \pm SEM of double-labeled neurons as a percentage of all Fos-labeled neurons. The total percentage does not necessarily add up to $100 \%$, possibly because of incomplete labeling with cell-type markers.

Role of accumbens shell neuronal ensembles in contextinduced reinstatement of cocaine seeking

The accumbens shell has been shown to play a role in contextinduced reinstatement of cocaine (Fuchs et al., 2008; Xie et al., 2012), heroin (Bossert et al., 2006, 2007), and alcohol (Chaudhri et al., 2009, 2010) seeking. We now show that only a small proportion $(3.3 \%)$ of accumbens shell neurons mediate contextinduced cocaine seeking. This finding, and our subsequent Daun02 inactivation results, support the hypothesis that during drug self-administration training, specific patterns of sparsely distributed neurons are selected by drug-associated contexts to form neuronal ensembles that encode learned associations between the contexts and drug effects (Cruz et al., 2013). In vivo electrophysiological recordings of single neurons during self-administration also suggest that different accumbens neurons are selectively activated by specific drug-associated contexts (and discrete cues) (Carelli et al., 1993; Peoples and West, 1996; Deadwyler et al., 2004; Opris et al., 2009; Guillem et al., 2013).

We used the Daun02 inactivation procedure (Koya et al., 2009; Cruz et al., 2013) to selectively inactivate neuronal ensembles in accumbens shell that were previously activated by the cocaine-associated context and assess their role in context- 
A

Timeline for Daun02 inactivation experiment

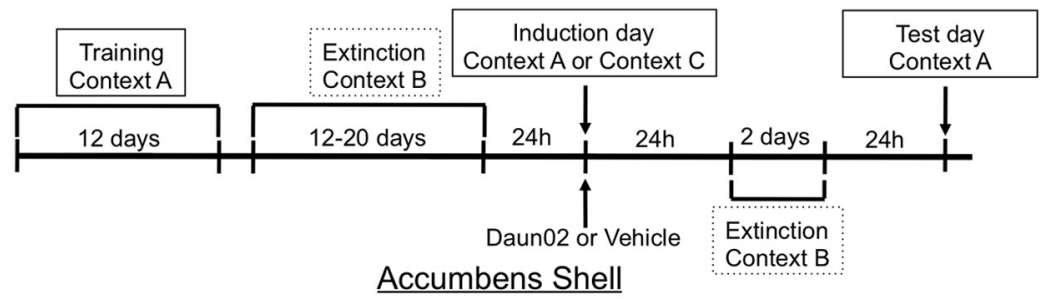

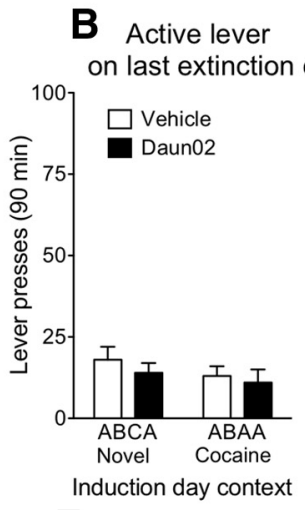

$\mathbf{E}$

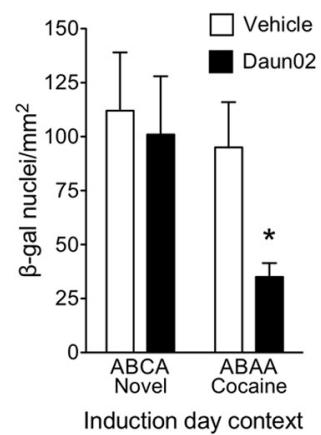

Accumbens Shell

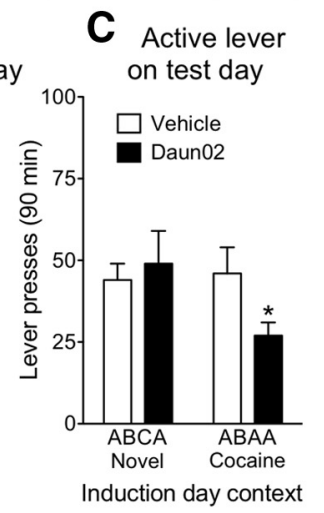

D Cannula placements

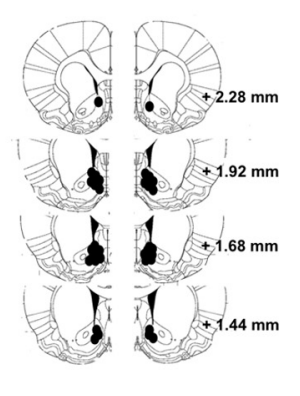

$\mathbf{F}$

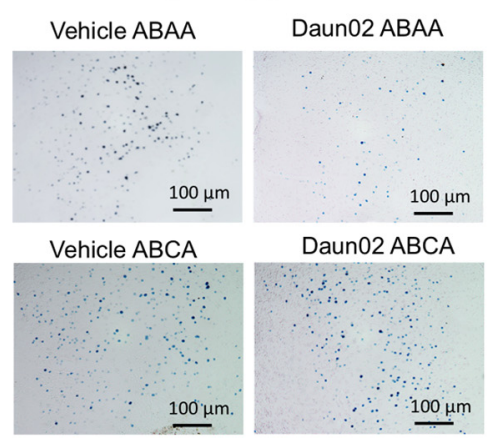

Figure 4. Daun02 inactivation of activated accumbens shell neurons decreased context-induced reinstatement of cocaine seeking. A, Timeline for Daun02 inactivation experiment. Cocaine self-administration training in Context A and extinction of cocaine seeking in Context B. On induction day, rats were exposed to the training Context A or a novel Context C, and injected bilaterally with Daun 02 or vehicle into the accumbens 90 min after the beginning of exposure. Context-induced reinstatement was assessed in Context A $3 \mathrm{~d}$ later. B, Total active lever-presses during the second day of extinction after vehicle or Daun02 injections. C, Total active lever-presses during context-induced reinstatement of cocaine seeking on test day. $\boldsymbol{D}$, Dots indicate approximate area of injector tip. $\boldsymbol{E}$, Accumbens shell $\beta$ gal expression after the context-induced reinstatement test. $\boldsymbol{F}$, Representative images of $\beta$ gal-labeled nuclei in accumbens shell. Data are mean \pm SEM. ${ }^{*} p<0.05$, different from vehicle-ABAA (Cocaine) group. $n=10$ or 11 per group.

Table 2. Number of inactive lever presses on the second day of extinction in Context $B$ and on test day in Context $A$ after vehicle or Daun02 injections in Context A or Context C on induction day ${ }^{a}$

\begin{tabular}{lllll}
\hline & $\begin{array}{l}\text { Extinction } \\
\text { vehicle } \\
\text { Context B }\end{array}$ & $\begin{array}{l}\text { Extinction } \\
\text { Daun02 } \\
\text { Context B }\end{array}$ & $\begin{array}{l}\text { Test day } \\
\text { vehicle } \\
\text { Context A }\end{array}$ & $\begin{array}{l}\text { Test day } \\
\text { Daun02 } \\
\text { Context A }\end{array}$ \\
\hline $\begin{array}{llll}\text { Shell } \\
\text { ABCA }\end{array}$ & $3.0 \pm 1.0$ & $3.0 \pm 1.0$ & $2.0 \pm 1.0$ & $4.0 \pm 1.0$ \\
ABAA & $3.0 \pm 1.0$ & $2.0 \pm 0.0$ & $5.0 \pm 1.0$ & $3.0 \pm 1.0$ \\
$\begin{array}{l}\text { Core } \\
\text { ABAA }\end{array}$ & $5.0 \pm 1.0$ & $4.0 \pm 1.0$ & $3.0 \pm 1.0$ & $4.0 \pm 1.0$ \\
\hline Data are mean \pm SEM. & & &
\end{tabular}

induced reinstatement of cocaine seeking. Context-induced $\beta$ gal expression and cocaine seeking on test day were attenuated by previous Daun02 inactivation of only those accumbens shell neurons that were selectively activated by the cocaine-associated
Context A. In contrast, Daun02 injections after exposure to the novel Context $\mathrm{C}$ had no effect on subsequent context-induced $\beta$ gal expression or context-induced cocaine seeking. These data rule out the possibility that Daun02 injections nonspecifically decreased accumbens shell neuronal activity during testing.

In a previous study, we used Daun02 injections after exposure to Context $\mathrm{B}$ as our control group (Bossert et al., 2011). The number of Fos- and $\beta$ gal-expressing neurons induced in Context B is generally very low in the brain areas that we have studied, which leaves open the possibility that Daun02 merely inactivated fewer neurons in the control group than in the Context A-exposed test group. In the current study, Fos expression in accumbens shell was much greater after exposure to a novel Context C. Despite inactivating a greater number of Fos- and $\beta$ galexpressing neurons in Context $\mathrm{C}$, this did not affect $\beta$ gal expression or cocaine seeking in Context A. Daun02 inactivation after exposure to a novel Context $C$ was also used as the control group to demonstrate that context-selected neuronal ensembles in orbitofrontal cortex neurons contribute to incubation of heroin craving (Fanous et al., 2012) and that neuronal ensembles in accumbens mediate context-specific sensitization (Koya et al., 2009). These observations strengthen the idea that the specific "pattern" of neurons selected by the drug-associated context is more important than the "number" of activated neurons.

An unresolved issue in our study is what psychological/learning process was affected by the Daun02 manipulation on induction day that led to decreased leverpresses during the context-induced reinstatement test day $3 \mathrm{~d}$ later. As discussed previously (Crombag et al., 2008), several psychological mechanisms may underlie the observed behavioral effects of Context A exposure on reinstatement of drug seeking in the ABA operant renewal procedure. One idea is that, during training, Context A becomes an excitatory Pavlovian conditioned stimulus that can increase nonreinforced operant responding during testing via a Pavlovian-toinstrumental transfer process (Lovibond, 1983). Another idea is that Contexts A and B can serve as occasion setters (Holland, 1992; Bouton, 1993) or discriminative stimuli (Kearns and Weiss, 2007) that predict when an operant response and the responsecontingent discrete cue will result in drug delivery or no drug. During the induction day, rats were exposed to Context A and lever-presses produced contingent tone-light cue delivery during the 30 min extinction tests. Therefore, as we did not attempt to experimentally separate the different psychological processes potentially involved in context-induced reinstatement, it is unknown whether the Daun02 manipulation inhibited neuronal ensembles that control the excitatory Pavlovian conditioning 
properties of Context A, the occasion setting or discriminative stimulus properties of this context, or both.

A surprising finding in our study was that Daun02 injections in accumbens core had no effect on context-induced reinstatement of cocaine seeking. This finding is different from those of previous studies where general inactivation of accumbens core with muscimol + baclofen or glutamate receptor antagonists attenuated context-induced reinstatement of cocaine seeking (Fuchs et al., 2008; Xie et al., 2012). The reasons for these different results are unknown, but one likely possibility is the different experimental conditions in our studies and those of Fuchs et al. (2008). Specifically, based on the work of Bouton and Bolles (1979), our studies were initially designed to test the ability of the drug-associated context to renew the rat's conditioned response to discrete injection-paired cues after extinction (Crombag and Shaham, 2002). Thus, in our studies, drug infusions during selfadministration training are paired with a discrete cue, and during extinction training and reinstatement tests, this cue is presented contingent on lever-presses. In contrast, explicit drug-paired cues are not presented during acquisition, extinction, and reinstatement tests (Fuchs et al., 2005).

This procedural difference is important because the presence or absence of discrete drug-paired cues during selfadministration training can potentially determine whether contexts directly induce drug seeking by acquiring excitatory Pavlovian conditioned stimulus properties, or indirectly induce drug seeking by modulating the effects of the discrete cues on drug seeking by serving as occasion setters (Crombag et al., 2008). There is evidence that these two learning mechanisms involve different brain mechanisms (Holland and Bouton, 1999). Thus, the different results on the role of accumbens core in context-induced reinstatement of cocaine seeking may be the result of the involvement of this accumbens region in excitatory contextual Pavlovian conditioning (Tzschentke, 2007) but not in contextual occasion setting.

Multiple cell types were activated by exposure to Contexts A and C. Most of the neurons activated by the cocaine context were GABAergic medium spiny neurons that comprised $69.4 \%$ of all the activated Fos-expressing neurons in accumbens shell. The remaining Fos-expressing neurons were GABAergic interneurons (calretinin, parvalbumumin, somatostatin) and cholinergic interneurons. The $24 \%$ proportion of Fos-expressing interneurons, particularly $13 \%$ parvalbumin interneurons, activated by the cocaine context is much higher than the anatomical proportion of these interneurons in the accumbens (Bolam et al., 2000; Tepper and Bolam, 2004; Voorn et al., 2004; Tepper et al., 2007). Overall, the mixture of cell types activated by Context $\mathrm{A}$ and Context $\mathrm{C}$ suggests that it is unlikely that contextinduced cocaine seeking was the result of activation of a particular cell type.

\section{Accumbens Core}

\section{B Active lever C Cannula placements} on test day
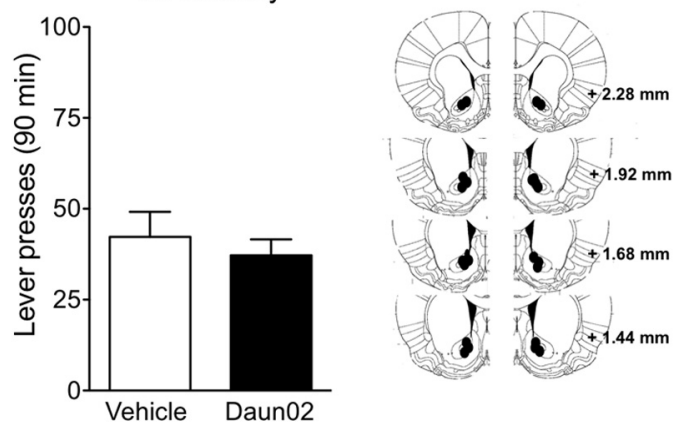

E

Images of $\beta$ gal nuclei

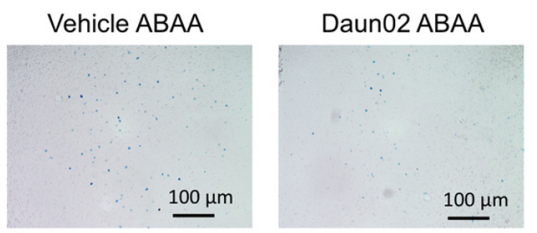

Medium spiny neurons and interneurons receive stimulispecific patterns of glutamatergic excitatory inputs from prefrontal cortex, amygdala, ventral subiculum, and intralaminar thalamic nucleus neurons (Meredith and Wouterlood, 1990; Zahm and Brog, 1992; Groenewegen and Berendse, 1994; Voorn et al., 2004). Along with ensembles in the accumbens shell, strongly activated neurons in these afferent brain areas are thought to form neuronal ensembles that encode learned associations underlying drug- and non-drug-related behaviors (Pennartz et al., 1994; Lee et al., 2009; Penner and Mizumori, 2012; Cruz et al., 2013). This could partly explain why Daun02 inactivation of accumbens shell ensembles only decreased contextinduced reinstatement of lever-pressing on test day by $\sim 40 \%$; ensembles from these other brain areas can contribute to the expression of context-induced reinstatement of cocaine seeking.

In conclusion, we used the pharmacogenetic Daun02 inactivation procedure to demonstrate a causal role of nucleus accumbens shell neuronal ensembles in context-induced cocaine seeking. Previous studies have shown causal roles for neuronal ensembles in the nucleus accumbens in context-specific locomotor sensitization (Koya et al., 2009), ventromedial prefrontal cortex in contextinduced reinstatement of heroin seeking (Bossert et al., 2011), and orbitofrontal cortex in cue-induced heroin seeking (Fanous et al., 2012). These studies support the hypothesis that context-selected neuronal ensembles encode learned associations between environmental contexts and drug effects and that activation of these ensembles plays a critical role in relapse to drug seeking during abstinence. 


\section{References}

Bäckman C, Morales M (2002) Acute methamphetamine administration upregulates NGFI-B mRNA expression in the striatum: co-localization with c-Fos immunoreactivity. Synapse 44:158-165. CrossRef Medline

Bolam JP, Hanley JJ, Booth PA, Bevan MD (2000) Synaptic organisation of the basal ganglia. J Anat 196:527-542. CrossRef Medline

Bossert JM, Liu SY, Lu L, Shaham Y (2004) A role of ventral tegmental area glutamate in contextual cue-induced relapse to heroin seeking. J Neurosci 24:10726-10730. CrossRef Medline

Bossert JM, Gray SM, Lu L, Shaham Y (2006) Activation of group II metabotropic glutamate receptors in the nucleus accumbens shell attenuates context-induced relapse to heroin seeking. Neuropsychopharmacology 31:2197-2209. CrossRef Medline

Bossert JM, Poles GC, Wihbey KA, Koya E, Shaham Y (2007) Differential effects of blockade of dopamine D1-family receptors in nucleus accumbens core or shell on reinstatement of heroin seeking induced by contextual and discrete cues. J Neurosci 27:12655-12663. CrossRef Medline

Bossert JM, Stern AL, Theberge FR, Cifani C, Koya E, Hope BT, Shaham Y (2011) Ventral medial prefrontal cortex neuronal ensembles mediate context-induced relapse to heroin. Nat Neurosci 14:420-422. CrossRef Medline

Bossert JM, Stern AL, Theberge FR, Marchant NJ, Wang HL, Morales M, Shaham Y (2012) Role of projections from ventral medial prefrontal cortex to nucleus accumbens shell in context-induced reinstatement of heroin seeking. J Neurosci 32:4982-4991. CrossRef Medline

Bouton ME (1993) Context, time, and memory retrieval in the interference paradigms of Pavlovian learning. Psychol Bull 114:80-99. CrossRef Medline

Bouton ME, Bolles RC (1979) Contextual control of the extinction of conditioned fear. Learn Motiv 10:445-466. CrossRef Medline

Bouton ME, Swartzentruber D (1991) Sources of relapse after extinction in Pavlovian and instrumental learning. Clin Psychol Rev 11:123-140. CrossRef

Carelli RM (2002) The nucleus accumbens and reward: neurophysiological investigations in behaving animals. Behav Cogn Neurosci Rev 1:281-296. CrossRef Medline

Carelli RM, King VC, Hampson RE, Deadwyler SA (1993) Firing patterns of nucleus accumbens neurons during cocaine self-administration in rats. Brain Res 626:14-22. CrossRef Medline

Chaudhri N, Sahuque LL, Janak PH (2009) Ethanol seeking triggered by environmental context is attenuated by blocking dopamine D1 receptors in the nucleus accumbens core and shell in rats. Psychopharmacology (Berl) 207:303-314. CrossRef Medline

Chaudhri N, Sahuque LL, Schairer WW, Janak PH (2010) Separable roles of the nucleus accumbens core and shell in context- and cue-induced alcohol-seeking. Neuropsychopharmacology 35:783-791. CrossRef Medline

Crombag HS, Shaham Y (2002) Renewal of drug seeking by contextual cues after prolonged extinction in rats. Behav Neurosci 116:169-173. CrossRef Medline

Crombag HS, Bossert JM, Koya E, Shaham Y (2008) Context-induced relapse to drug seeking: a review. Philos Trans R Soc Lond B Biol Sci 363: 3233-3243. CrossRef Medline

Cruz FC, Koya E, Guez-Barber DH, Bossert JM, Lupica CR, Shaham Y, Hope BT (2013) New technologies for examining the role of neuronal ensembles in drug addiction and fear. Nat Rev Neurosci 14:743-754. CrossRef Medline

Deadwyler SA, Hayashizaki S, Cheer J, Hampson RE (2004) Reward, memory and substance abuse: functional neuronal circuits in the nucleus accumbens. Neurosci Biobehav Rev 27:703-711. CrossRef Medline

Fanous S, Goldart EM, Theberge FR, Bossert JM, Shaham Y, Hope BT (2012) Role of orbitofrontal cortex neuronal ensembles in the expression of incubation of heroin craving. J Neurosci 32:11600-11609. CrossRef Medline

Farquhar D, Pan BF, Sakurai M, Ghosh A, Mullen CA, Nelson JA (2002) Suicide gene therapy using E. coli beta-galactosidase. Cancer Chemother Pharmacol 50:65-70. CrossRef Medline

Fuchs RA, Evans KA, Ledford CC, Parker MP, Case JM, Mehta RH, See RE (2005) The role of the dorsomedial prefrontal cortex, basolateral amygdala, and dorsal hippocampus in contextual reinstatement of cocaine seeking in rats. Neuropsychopharmacology 30:296-309. CrossRef Medline
Fuchs RA, Ramirez DR, Bell GH (2008) Nucleus accumbens shell and core involvement in drug context-induced reinstatement of cocaine seeking in rats. Psychopharmacology 200:545-556. CrossRef Medline

Groenewegen HJ, Berendse HW (1994) The specificity of the 'nonspecific' midline and intralaminar thalamic nuclei. Trends Neurosci 17:52-57. CrossRef Medline

Guillem K, Ahmed SH, Peoples LL (2013) Escalation of cocaine intake and incubation of cocaine seeking are correlated with dissociable neuronal processes in different accumbens subregions. Biol Psychiatry pii:S0006. CrossRef Medline

Hamlin AS, Clemens KJ, McNally GP (2008) Renewal of extinguished cocaine seeking. Neuroscience 151:659-670. CrossRef Medline

Holland PC (1992) Occasion setting in Pavlovian conditioning. In: The psychology of learning and motivation (Medlin DL, ed), pp 69-125. San Diego: Academic.

Holland PC, Bouton ME (1999) Hippocampus and context in classical conditioning. Curr Opin Neurobiol 9:195-202. CrossRef Medline

Kasof GM, Mandelzys A, Maika SD, Hammer RE, Curran T, Morgan JI (1995) Kainic acid-induced neuronal death is associated with DNA damage and a unique immediate-early gene response in c-fos-lacZ transgenic rats. J Neurosci 15:4238-4249. Medline

Kearns DN, Weiss SJ (2007) Contextual renewal of cocaine seeking in rats and its attenuation by the conditioned effects of an alternative reinforcer. Drug Alcohol Depend 90:193-202. CrossRef Medline

Koya E, Golden SA, Harvey BK, Guez-Barber DH, Berkow A, Simmons DE, Bossert JM, Nair SG, Uejima JL, Marin MT, Mitchell TB, Farquhar D, Ghosh SC, Mattson BJ, Hope BT (2009) Targeted disruption of cocaineactivated nucleus accumbens neurons prevents context-specific sensitization. Nat Neurosci 12:1069-1073. CrossRef Medline

Lasseter HC, Xie X, Ramirez DR, Fuchs RA (2010) Prefrontal cortical regulation of drug seeking in animal models of drug relapse. Curr Top Behav Neurosci 3:101-117. CrossRef Medline

Lee E, Oliveira-Ferreira AI, de Water E, Gerritsen H, Bakker MC, Kalwij JA, van Goudoever T, Buster WH, Pennartz CM (2009) Ensemble recordings in awake rats: achieving behavioral regularity during multimodal stimulus processing and discriminative learning. J Exp Anal Behav 92: 113-129. CrossRef Medline

Lovibond PF (1983) Facilitation of instrumental behavior by a Pavlovian appetitive conditioned stimulus. J Exp Psychol Anim Behav Process 9:225-247. CrossRef Medline

Marchant NJ, Millan EZ, McNally GP (2012) The hypothalamus and the neurobiology of drug seeking. Cell Mol Life Sci 69:581-597. CrossRef Medline

Meredith GE, Wouterlood FG (1990) Hippocampal and midline thalamic fibers and terminals in relation to the choline acetyltransferaseimmunoreactive neurons in nucleus accumbens of the rat: a light and electron microscopic study. J Comp Neurol 296:204-221. CrossRef Medline

Meredith GE, Agolia R, Arts MP, Groenewegen HJ, Zahm DS (1992) Morphological differences between projection neurons of the core and shell in the nucleus accumbens of the rat. Neuroscience 50:149-162. CrossRef Medline

Morales M, Criado JR, Sanna PP, Henriksen SJ, Bloom FE (1998) Acute ethanol induces c-fos immunoreactivity in GABAergic neurons of the central nucleus of the amygdala. Brain Res 798:333-336. CrossRef Medline

Mullen RJ, Buck CR, Smith AM (1992) NeuN, a neuronal specific nuclear protein in vertebrates. Development 116:201-211. Medline

Neisewander JL, Baker DA, Fuchs RA, Tran-Nguyen LT, Palmer A, Marshall JF (2000) Fos protein expression and cocaine seeking behavior in rats after exposure to a cocaine self-administration environment. J Neurosci 20:798-805. Medline

O’Brien C, Childress AR, Ehrman R, Robbins S, McLellan AT (1992) Conditioning mechanisms in drug dependence. Clin Neuropharmacol 15 [Suppl 1]:66A-67A.

Opris I, Hampson RE, Deadwyler SA (2009) The encoding of cocaine vs natural rewards in the striatum of nonhuman primates: categories with different activations. Neuroscience 163:40-54. CrossRef Medline

Paxinos G, Watson C (2005) The rat brain in stereotaxic coordinates, Ed 5. Amsterdam: Elsevier Academic.

Pennartz CM, Groenewegen HJ, Lopes da Silva FH (1994) The nucleus accumbens as a complex of functionally distinct neuronal ensembles: an 
integration of behavioural, electrophysiological and anatomical data. Prog Neurobiol 42:719-761. CrossRef Medline

Penner MR, Mizumori SJ (2012) Neural systems analysis of decision making during goal-directed navigation. Prog Neurobiol 96:96-135. CrossRef Medline

Peoples LL, West MO (1996) Phasic firing of single neurons in the rat nucleus accumbens correlated with the timing of intravenous cocaine selfadministration. J Neurosci 16:3459-3473. Medline

Tepper JM, Bolam JP (2004) Functional diversity and specificity of neostriatal interneurons. Curr Opin Neurobiol 14:685-692. CrossRef Medline

Tepper JM, Abercrombie ED, Bolam JP (2007) Basal ganglia macrocircuits. Prog Brain Res 160:3-7. CrossRef Medline

Tzschentke TM (2007) Measuring reward with the conditioned place preference (CPP) paradigm: update of the last decade. Addict Biol 12:227462. CrossRef Medline

Voorn P, Vanderschuren LJ, Groenewegen HJ, Robbins TW, Pennartz CM
(2004) Putting a spin on the dorsal-ventral divide of the striatum. Trends Neurosci 27:468-474. CrossRef Medline

Woodward DJ, Chang JY, Janak P, Azarov A, Anstrom K (1999) Mesolimbic neuronal activity across behavioral states. Ann N Y Acad Sci 877:91-112. CrossRef Medline

Xie X, Lasseter HC, Ramirez DR, Ponds KL, Wells AM, Fuchs RA (2012) Subregion-specific role of glutamate receptors in the nucleus accumbens on drug context-induced reinstatement of cocaine seeking behavior in rats. Addict Biol 17:287-299. CrossRef Medline

Zahm DS (1992) An electron microscopic morphometric comparison of tyrosine hydroxylase immunoreactive innervation in the neostriatum and the nucleus accumbens core and shell. Brain Res 575:341-346. CrossRef Medline

Zahm DS, Brog JS (1992) On the significance of subterritories in the "accumbens" part of the rat ventral striatum. Neuroscience 50:751-767. CrossRef Medline 